\title{
Identificação de Fatores Socioeconômicos que Influenciaram a Evasão de Acadêmicos do Curso de Licenciatura em Matemática da Universidade Estadual do Oeste do Paraná - Campus Cascavel
}

\author{
Aldioni Adaiani Andreta \\ Universidade Estadual do Oeste do Paraná - Departamento de Matemática \\ Campus de Cascavel, PR \\ E-mail: aldioniadaiani@hotmail.com \\ Rosangela Villwock \\ Universidade Estadual do Oeste do Paraná - Departamento de Matemática \\ Campus de Cascavel, PR \\ E-mail: rosangelamat@hotmail.com
}

\begin{abstract}
RESUMO
Este trabalho teve por objetivo identificar os fatores socioeconômicos que influenciam na tomada de decisão do acadêmico em abandonar o curso de Matemática da Universidade Estadual do Oeste do Paraná - Campus de Cascavel. O trabalho foi realizado com acadêmicos que estavam matriculados em 2012, os que permaneceram matriculados em 2013 e os que abandonaram em 2012. Foi aplicado um questionário que abordou questões socioeconômicas como renda familiar, participação no orçamento doméstico, gasto com a graduação, cidade de residência, moradia, entre outras. Utilizou-se da tarefa de classificação e aplicou-se o algoritmo J48.J48, implementado no WEKA, para gerar Árvores de Decisão. Foi possível observar os principais fatores que contribuíram para a evasão no curso.
\end{abstract}

Palavras-chave: Evasão, Classificação, Árvores de Decisão.

\section{INTRODUÇÃO}

A evasão no ensino superior, segundo Silva Filho et al. (2007), é um problema de nível internacional que afeta o resultado dos sistemas educacionais. As perdas, relacionadas a estudantes que iniciam um curso, mas não o concluem, representam desperdícios sociais, acadêmicos e econômicos. No setor público, representa recursos públicos investidos sem o devido retorno.

Como em muitas outras universidades, o alto número de abandonos é uma realidade na Universidade Estadual do Oeste do Paraná - UNIOESTE. Dados fornecidos pela Pró-Reitoria de Graduação retratam a realidade da evasão nos quatro cursos pertencentes ao CCET-Centro de Ciências Exatas e Tecnológicas, Campus de Cascavel (ao qual pertence o curso de Licenciatura em Matemática, objeto de estudo do presente trabalho) nos últimos cinco anos. Em média, são 68 abandonos por ano.

No curso de Licenciatura em Matemática são oferecidas 40 vagas anualmente para ingresso de estudantes no período noturno. O número de conclusões a cada ano no curso é muito baixo e o número de alunos que abandonam o curso é elevado. No gráfico da Figura 01, pode-se verificar o número de evadidos anualmente no período entre 2008 a 2012. 


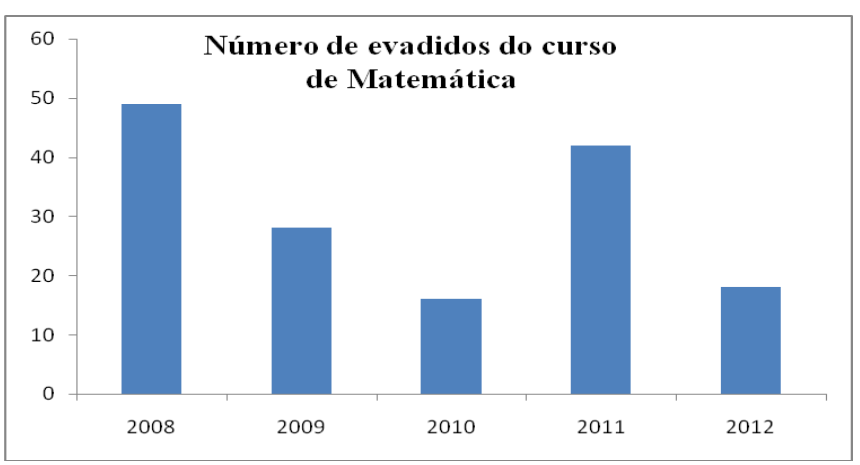

Figura 01 - Número de evadidos do curso de Matemática - últimos 5 anos

Souza (2008) relata que as causas para a evasão podem ir desde um impedimento ou dificuldade séria, à falta de motivação ligada à própria realização do curso ou ao contexto sócio-individual ou do ambiente.

Gaioso (2005) apresenta alguns problemas que levam a evasão, indicados pelos alunos: falta de orientação vocacional, imaturidade do estudante, reprovações sucessivas, dificuldades financeiras, falta de perspectiva de trabalho, ausência de laços afetivos na universidade, ingresso na faculdade por imposição familiar, casamentos não planejados e nascimento de filhos.

Este trabalho teve por objetivo identificar os fatores socioeconômicos que possam influenciar na tomada de decisão do acadêmico em abandonar o curso de Matemática da Universidade Estadual do Oeste do Paraná - Campus de Cascavel. O trabalho foi realizado com acadêmicos que estavam matriculados em 2012, os que permaneceram matriculados em 2013 e os que abandonaram em 2012. Foi aplicado um questionário que abordou questões socioeconômicas como renda familiar, participação no orçamento doméstico, gasto com a graduação, cidade de residência, moradia, entre outras.

\section{O PROCESSO KDD}

Segundo Tan et al. (2012) o termo KDD - Knowledge Discovery in Database (Descoberta de Conhecimento em Base de Dados) foi estabelecido no primeiro workshop de KDD em 1989 para enfatizar que conhecimento é o produto final de uma descoberta baseada em dados. Desta forma KDD se refere a todo o processo de descoberta de conhecimento

Tan et al. (2012) afirmam que neste processo estão envolvidas várias etapas que vão desde a seleção da base de dados até a disponibilização do conhecimento descoberto para o usuário. Em um alto nível de abstração pode-se dizer que essas etapas fazem parte de três grandes grupos: pré-processamento, aplicação de um algoritmo de Mineração de dados e pós-processamento.

As tarefas de Mineração de Dados podem ser preditivas, que usam algumas variáveis para prever valores desconhecidos; ou descritivas, que encontram padrões para descrever os dados. As principais tarefas de Mineração de Dados estão relacionadas à Classificação, Regras de Associação, e Análise de Agrupamento (FAYYAD et al., 1996). A tarefa utilizada neste trabalho foi a Classificação.

Segundo Tan et al. (2012) a classificação é uma abordagem sistemática para a construção de modelos de classificação a partir de um conjunto de dados de entrada. Cada padrão contém um conjunto de atributos e um dos atributos é denominado classe. O objetivo da classificação é encontrar um modelo para predição da classe como função dos outros atributos:

Segundo Gonçalves (2011) o objetivo da Classificação é, a partir de um banco de dados contendo objetos pré-classificados (objetos cuja classe é conhecida), construírem um modelo 
que seja capaz de classificar automaticamente novos objetos (objetos cuja classe é desconhecida) em função de suas características.

\section{RESULTADOS E DISCUSSÕES}

Para este trabalho, 41 pessoas responderam o questionário, sendo que 32 estão matriculados em 2013 e nove evadiram em 2012. Foi utilizado o software Weka e aplicado o algoritmo J48.J48 para gerar árvores de decisão. A Árvore de Decisão, representada na Figura 02 , tem precisão de $82 \%$.

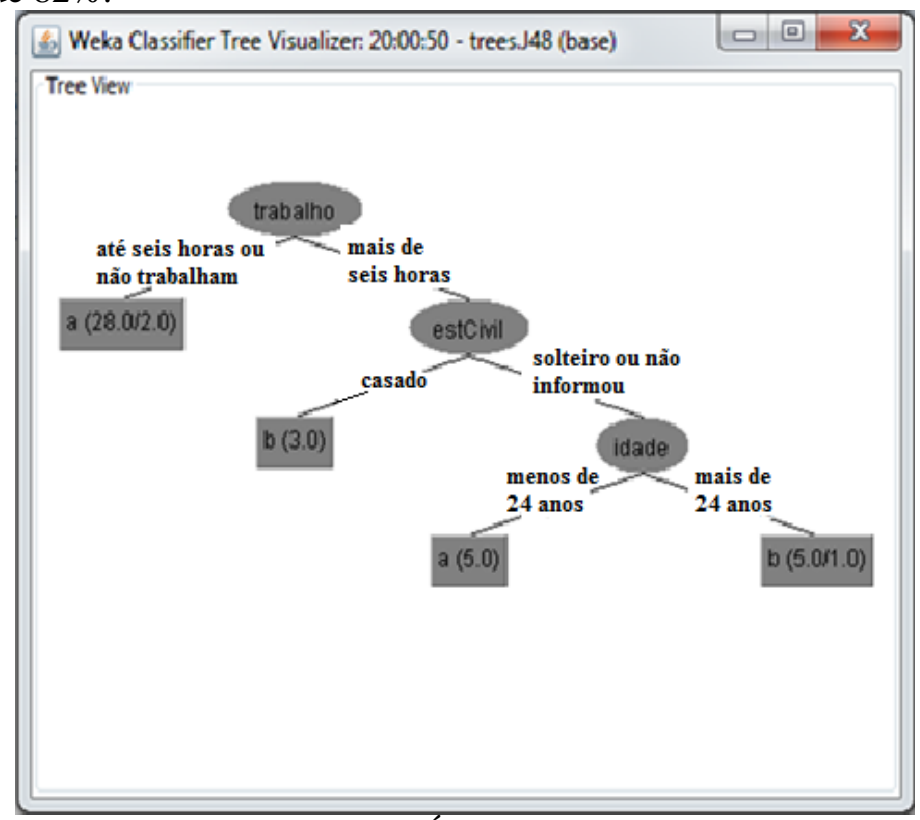

Figura 02 - Árvore de decisão

Fazendo a interpretação da Árvore de Decisão, conclui-se que o acadêmico que não trabalha não abandona o curso. Esta regra foi alcançada por 28 acadêmicos e não foi válida para apenas dois. Desta forma, o fato de não trabalhar foi um fator relevante para a permanência no curso.

A segunda variável mais relevante foi o estado civil. Se além de trabalhar o acadêmico for casado, o mesmo abandonou o curso. Esta regra foi alcançada por três acadêmicos.

Por fim, a idade também teve contribuição para a evasão, visto que acadêmicos que trabalhavam e não eram casados mas que tinham idade maior de 24 anos decidiram por abandonar o curso. Esta regra foi alcançada por cinco acadêmicos e não foi válida para apenas um.

\section{CONSIDERAÇÕES FINAIS}

Com base nos resultados obtidos podemos afirmar que o fato do acadêmico ter que trabalhar, para se sustentar ou sustentar a família acaba sendo o fator principal para o abandono.

Espera-se assim com este trabalho poder contribuir para a elaboração de projetos que visem garantir a permanência dos acadêmicos no curso. Entre as ações esperadas pode-se citar a criação de Restaurante Universitário, o que ajudaria na diminuição dos gastos dos acadêmicos e a ampliação do número de bolsas (de Iniciação Científica, Monitoria Acadêmica ou Iniciação a Docência), dando mais oportunidades aos acadêmicos de se manterem sem a necessidade de trabalhar.

\section{REFERENCIAS}


FAYYAD, U. M.; PIATETSKY-SHAPIRO, G.; SMYTH, P.; UTHRUSAMY, R. Advances in Knowledge Discovery \& Data Mining. Califórnia: AAAI/MIT, 1996.

GAIOSO, N. P. L. O fenômeno da evasão escolar na educação superior no Brasil. 2005. 75 f. Dissertação (Mestrado em Educação) - Programa de Pós-Graduação em Educação da Universidade Católica de Brasília, Brasília, 2005.

GONÇALVES, C.E. Data Mining com a ferramenta Weka. Fórum de Software Livre de Duque de Caxias - 2011.

SILVA FILHO, R. L. L. E; MOTEJUNAS, P. R.; HIPÓLITO, O.; LOBO, M. B. DE C. M. A EVASÃO NO ENSINO SUPERIOR BRASILEIRO. Cadernos de Pesquisa, v. 37, n. 132, p. $641-659,2007$.

SOUZA, S. L. "Evasão No Ensino Superior: Um Estudo Utilizando A Mineração De Dados Como Ferramenta De Gestão Do Conhecimento Em Um Banco de Dados Referente À Graduação De Engenharia.” Dissertação de Mestrado. Coppe - UFRJ, Rio de Janeiro, 2008.

TAN, P - N; STEINBACH, M.; KUMAR, V. Introdução ao DATA MINING Mineração de Dados. Rio de Janeiro: Editora Ciência Moderna Ltda., 2012. 